NASZA DERMATOLOGIA Online OUR DERMATOLOGY Online

Source of Support: Nil

Competing Interests: None declared

\section{LINEAR LICHEN PLANUS PIGMENTOSUS AND COINCIDENTAL IPSILATERAL FACIAL NERVE PALSY: AN UNUSUAL OBSERVATION}

\author{
Iffat Hassan, Parvaiz Anwar Rather, Peerzada Sajad \\ Department of Dermatology, STD and Leprosy, Government Medical College, \\ Srinagar (University of Kashmir), J\&K, India
}

Corresponding author: Associate Professor Iffat Hassan

hassaniffat@gmail.com
Sir,

A 30 year old male from West Bengal, presented to our outpatient department on 28th June 2012, with 5 months duration of asymptomatic pigmentation in a linear fashion on left side of face and forehead, which started as a small pigmented spot on left side of glabella and gradually increased in size. There was no history of trauma, photosensitivity, preceding skin eruptions, significant drug or family history. In 2009, patient had suffered from left side idiopathic facial palsy (Bells palsy) which has improved considerably now. General physical and systemic examination was normal. Cutaneous examination showed unilaterally distributed, non scaly, non atrophic, linear streak of bluish-black pigmentation, continuous and interrupted, extending from left side of vertex of scalp, through forehead to side of nose and upper lip (Fig. 1a, b). There was slight facial asymmetry with left side flatter than that of right side along with other features of a mild left sided facial palsy (Fig. 2a, b). Hair, nail and mucus membrane examination was normal. With a differential diagnosis of lichen planus pigmentosus (LPP), ashy dermatosis, linear epidermal nevus, linear LP, a punch skin biopsy was taken and sent for histopathologic examination, which under haematoxylin and eosin staining showed pigment incontinence, colloid bodies, basal vacuolation and lymphocytic exocytosis without eosinophils, suggesting the diagnosis of LPP (Fig. 3a, b). Absence of prior papular eruption helped us to rule out lichen planus and classical histopathologic findings pointed to the diagnosis of lichen planus pigmentosus (LPP). Nothing abnormal was found in complete blood count, liver function test, kidney function tests and hepatitis B \& C serology. Thus we report the rare case of linear LPP in a patient with same side facial nerve palsy as a coincidental finding.

Lichen planus, a papulosquamous disease, is classically characterized by pruritic, violaceous papules with many clinical variants. Linear lichen planus is a well defined entity with many case reports [1,2]. Similarly, lichen planus pigmentosus (LPP), first described by Bhutani et al. [3], is a rare variant of lichen planus, and appears as mottled or reticulated hyperpigmented, dark brown macules or papules most common on sun exposed areas such as the face, neck and flexural folds [4,5]. Less common presentations include zosteriform pattern on the trunk [6], linear unilateral lesion on the extremity [7] and involvement of non sun-exposed areas such as thigh [8]. The cause of LPP is unknown, but an immunologic mechanism mediates its development, as well as that of lichen planus [9]. Clinically, LPP differs from classical lichen planus by exhibiting dark brown macules and a longer clinical course without pruritus or scalp, nail, or mucosal involvement [3]. LPP is a close differential diagnosis of erythema dyschromicum perstans (ashy dermatosis) [10]. The relation of EDP to lichen planus (LP) is uncertain, both have several clinical, histological and immunohistochemical similarities and often coexist, making some authors consider EDP a variant of LP [11].

Linear LPP is considered as a combined type of linear lichen planus and LPP and there have been only a few reports on this in the dermatologic literature [12-15], especially from India [16]. The linearity of the lesion is probably related to Blaschko's lines, which suggests that the predisposition to develop LPP might be determined during embryogenesis [2]. The clinical coexistence of same side facial nerve palsy preceding the linear lesions of LPP found in our case seems to be just a coincidence.

\section{REFERENCES}

1. Long CC, Finlay AY: Multiple linear lichen planus in the lines of Blaschko. Br J Dermatol. 1996;135:275-6.

2. Park HJ, Lee YS: A case of multiple linear lichen planus along the lines of Blaschko. Korean J Dermatol. 2006;44:627-9. 
3. Bhutani LK, Bedi TR, Pandhi RK, Nayak NC: Lichen planus pigmentosus. Dermatologica. 1974;149:43-50.

4. Kanwar AJ, Dogra S, Handa S, Parsad D, Radotra BD: A study of 124 Indian patients with lichen planus pigmentosus. Clin Exp Dermatol. 2003;28:481-5.

5. Pock L, Jelínková L, Drlík L, Abrhámová S, Vojtechovská S, Sezemská D, et al: Lichen planus pigmentosus-inversus. J Eur Acad Dermatol Venereol. 2001;15:452-4.

6. Cho S, Whang KK: lichen planus pigmentosus presenting in zosteriform pattern. J Dermatol. 1997;24:193-7.

7. Akagi A, Ohnishi Y, Tajima S, Ishibashi A: Linear hyperpigmentation with extensive epidermal apoptosis: a variant of linear lichen planus pigmentosus? J Am Acad Dermatol. 2004;50:78-80.

8. Kim KJ, Bae GY, Choi JH, Sung KJ, Moon KC, Koh JK: A case of localized lichen planus pigmentosus on the thigh. J Dermatol. 2002;29:242-3.

9. Krasowska D, Schwartz RA, Lecewicz-Torun B: Generalized lichenoid drug eruption following Blaschko lines. Int J Dermatol. 2001;40:774-6.
10. Chakrabarti N, Chattopadhyay C: Ashy dermatosis: A controversial entity. Indian J Dermatol. 2012;57:61-2.

11. Bhutani LK: Ashy dermatosis or lichen planus pigmentosus. What is in a name? Arch Dermatol. 1986;122:133.

12. Hong S, Shin JH, Kang HY: Two cases of lichen planus pigmentosus presenting with a linear pattern. J Korean Med Sci. 2004; 19:152-154.7.

13. Ji JH, Park HY, Kim JH, Hong SP, Bak H, Lee SH, et al: A case of lichen planus pigmentosus along the lines of Blaschko. Korean J Dermatol. 2009;47:313-6.

14. Seo JK, Lee HJ, Lee D, Choi JH, Sung HS: A case of linear lichen planus pigmentosus. Ann Dermatol. 2010;22:323-5.

15. Ru-zhi Zhang, Wen-yuan Zhu: One Case of Unilateral Linear Lichen Planus Pigmentosus. Open Dermatol J. 2012;6:25-8.

16. Wani AA, Nighat Jan: Lichen Planus Pigmentosus with a Linear Pattern. Iran J Dermatol. 2009;12:134-5.
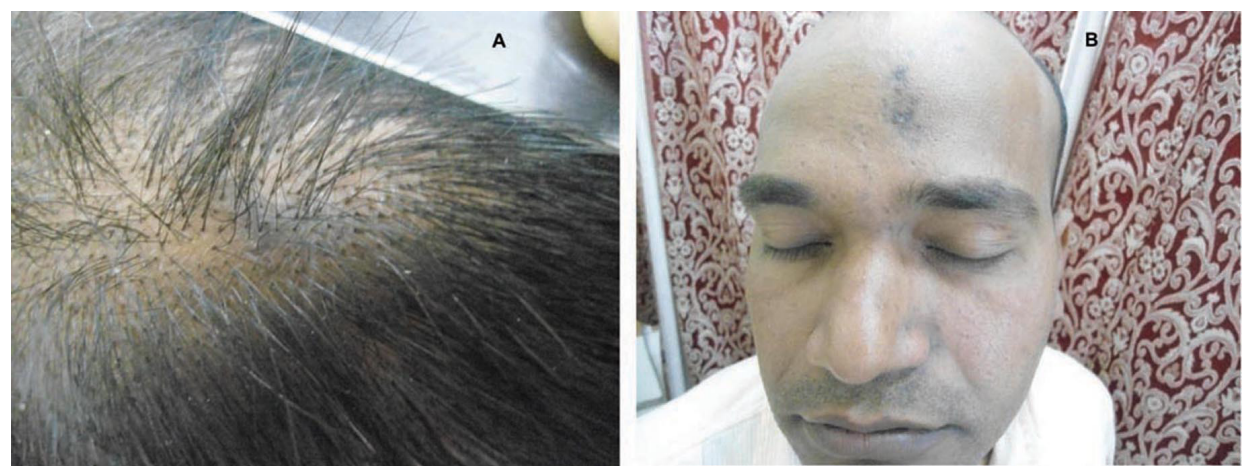

Figure 1a,b. Linear streak of bluish-black pigmentation, extending from left side of vertex of scalp (a), through forehead to side of nose and upper lip (b).

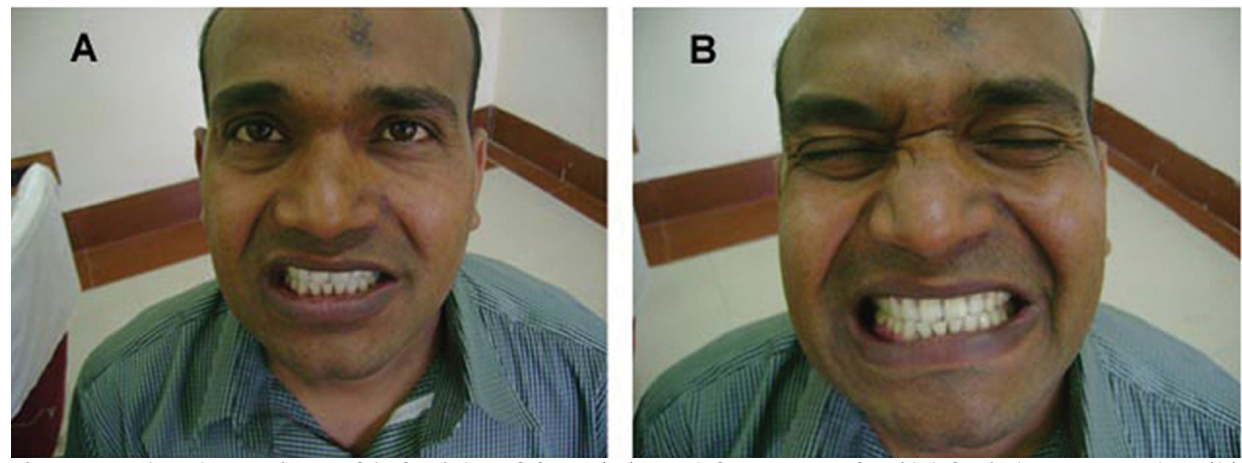

Figure 2a,b. Flattening of left side of face (A) and features of mild facial nerve palsy (b).
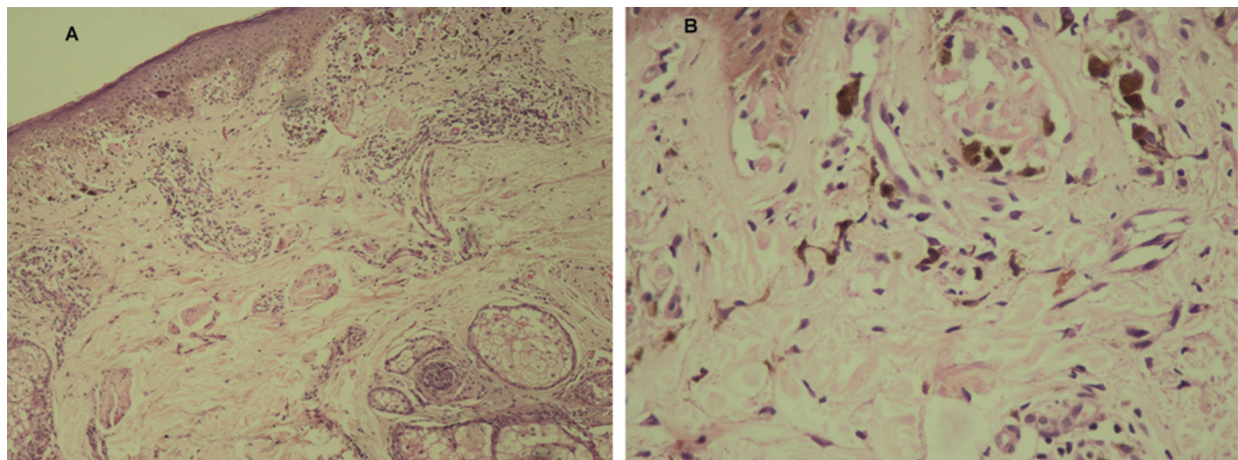

Figure 3a,b. Photomicrograph showing pigment incontinence, colloid bodies, basal vacuolation and lymphocytic exocytosis without eosinophils. H\&E; 10X (Fig. a), 40X (Fig. b).

Copyright by Iffat Hassan, et al This is an open access article distributed under the terms of the Creative Commons Attribution License, which permits unrestricted use, distribution, and reproduction in any medium, provided the original author and source are credited. 